\title{
A Novel Bridgeless Single-Stage Step-Up Rectifier
}

\author{
Yi Li *, Joon-Hyeok Jeon* and Hee-Jun Kim ${ }^{\dagger}$
}

\begin{abstract}
This paper proposes a novel bridgeless single-stage step-up voltage rectifier. Rectification, voltage step-up, and power factor correction functions can all be achieved in a single-stage circuit. The proposed circuit could be used as a power supply for high-voltage battery chargers. The proposed circuit topology is based on a conventional voltage doubler. Two voltage doublers are connected in parallel for reducing the output voltage ripple. Two pairs of thyristors are implemented instead of the original diode for controlling the circuit. The analysis of the circuit operating process is demonstrated, and a prototype is built and tested. The experimental results verify that the proposed rectifier has good boost ratio, output voltage ripple, and power efficiency and an acceptable power factor function.
\end{abstract}

Keywords: Voltage doubler, Thyristor, Power factor correction, Bridgeless rectifier

\section{Introduction}

Nowadays, high-voltage dc power supplies are widely used for industrial, scientific, and military applications. In particular, they are used in test equipment such as accelerators, lasers, battery chargers, X-ray machines, dcmachine drivers, and electronic loads [1-3]. However, the conventional implementation usually contains a bridge rectifier and a DC-DC boost converter, as shown in Fig.1 [4]. The current flows through bridge diodes in addition to the switching component of the DC-DC converter, which results in higher conduction losses. In this paper, a novel bridgeless single-stage step-up rectifier is proposed and analyzed. Fig.2 shows the topology of the proposed circuit. The circuit has two voltage doublers connected in parallel, which guarantees that the output voltage ripple will be interleaved. Therefore, the ripple can be mitigated. The voltage stress over one output capacitor is also reduced to half of the output voltage, which reduces the capacitor size. Two pairs of thyristors are implemented instead of the original diodes in voltage doublers for regulating the output voltage [5-7]. By changing the firing angle of the thyristor, the output voltage can be controlled. The ac input side has an inductor for achieving a passive power factor function. A TCA785 phase control chip is used to control the proposed circuit [8]. It ensures that the gate signals of two pairs of thyristors are in a complementary mode, and it is also synchronized with the line frequency ac input voltage. The operating principles and theoretical analysis of the proposed circuit are given. The experimental results of a $1000 \mathrm{~W}$ prototype are presented to verify the performance of the proposed topology.

$\dagger$ Corresponding Author: Dept. of Electronic Systems Engineering, Hanyang University, Korea. (hjkim@hanyang.ac.kr)

* Dept. of Electronic Systems Engineering, Hanyang University,

Korea. (littlepear@hanyang.ac.kr, joonhyeok24@naver.com)

Received: January 18, 2016; Accepted: April 6, 2016

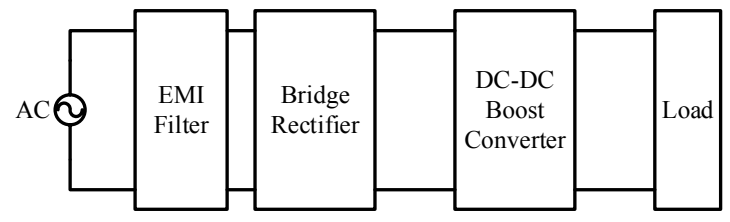

Fig. 1. Block diagram of conventional two-stage boost rectifier with $\mathrm{PFC}$ function

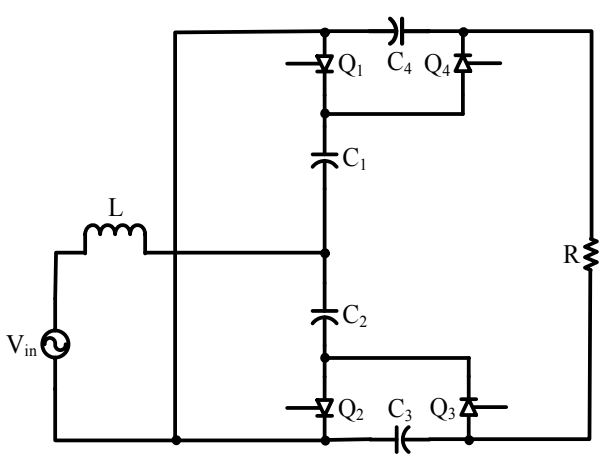

Fig. 2. Proposed circuit topology

\section{Operating principle of proposed circuit}

Fig. 3 shows the firing sequence of the thyristors in the proposed circuit.

Fig. 4 shows the operating principle of the proposed circuit. In phase $1, \mathrm{Q}_{2}$ and $\mathrm{Q}_{4}$ are triggered. However, only $\mathrm{Q}_{4}$ conducts, because $\mathrm{Q}_{2}$ is still reversely biased. Energy from the ac source and $\mathrm{C}_{1}$ flows into capacitor $\mathrm{C}_{4}$. Energy from the ac source, $C_{1}$, and $C_{3}$ flows into the load. In phase $2, \mathrm{Q}_{2}$ conducts. Energy from the source also charges capacitor $\mathrm{C}_{2}$. In phase 3 , all thyristors are blocked, and energy circulates through $\mathrm{C}_{3}, \mathrm{C}_{4}$, and the load. In phase 4 to phase 6 , the ac voltage is in the negative half cycle, and therefore, the operating principle is opposite to that in phase 1 to 3 
The typical waveforms of the circuit are shown in Fig. 5. This figure shows the ac input voltage, inductor current, switch current of $\mathrm{Q}_{4}$, switch current of $\mathrm{Q}_{1}$, capacitor voltage $V_{C 3}$, capacitor voltage $V_{C 4}$, and output voltage $V_{o}$ from the top. In this figure, p1 to p6 denote phase 1 to phase 6 , respectively.

As shown in the figure, the output voltage consists of two interleaved capacitor voltages, as a result of which the output voltage ripple can be reduced considerably.

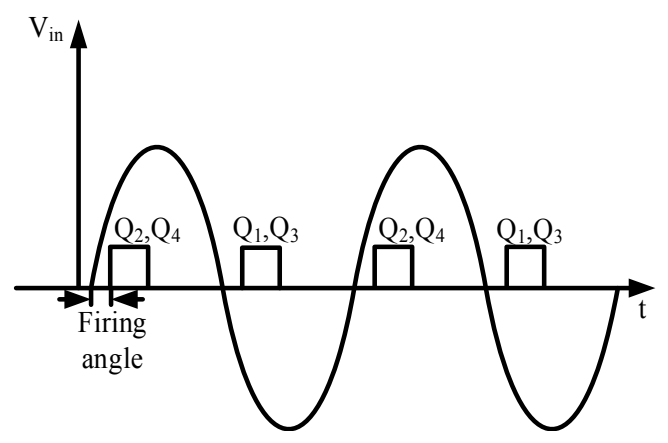

Fig. 3. Firing sequence of thyristors

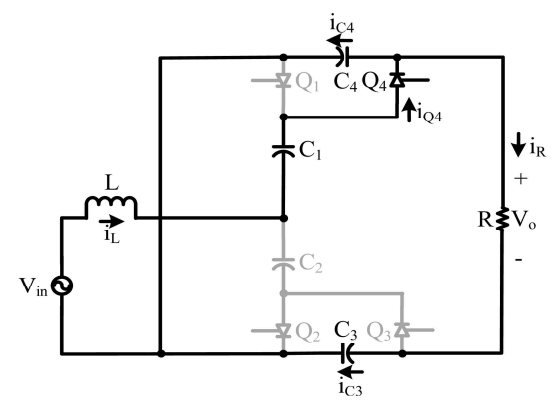

(a) phase 1

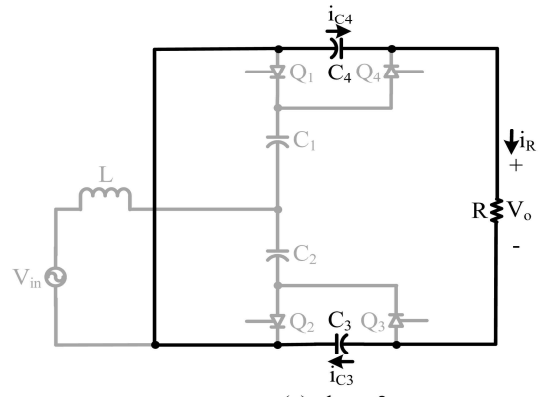

(c) phase 3

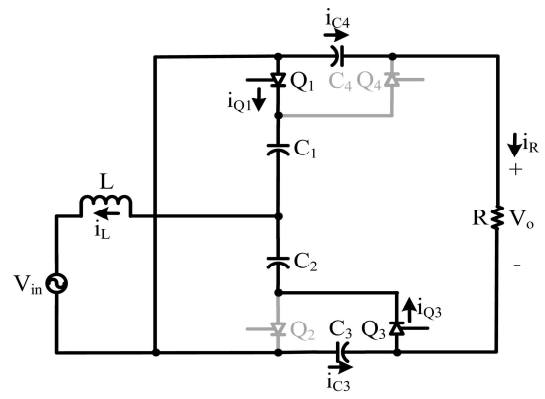

(e) phase 5

\section{Theoretical analysis}

Theoretically, a conventional voltage doubler provides dc voltage with two times the magnitude of the ac voltage source under no load condition [9-12]. In our circuit, we connect two voltage doublers in parallel, and therefore, the output voltage ripple of two capacitors can be interleaved. The maximum output voltage of our circuit should be four times the magnitude of the ac voltage source under no load condition. Considering that the firing angle of the thyristors can be changed to control the output voltage, the output voltage can be expressed as follows:

$$
V_{o}=4 \times V_{m}
$$

where $\mathrm{V}_{\mathrm{m}}$ is the maximum voltage in the time duration between the firing point and the zero-crossing point. A detailed explanation for $\mathrm{V}_{\mathrm{m}}$ is shown in Fig. 6. As an example, two different maximum voltages for angles of $30^{\circ}$ and $135^{\circ}$ are shown. For an input voltage of $V_{\text {in }}=110$ $\mathrm{V}$ rms, under no load condition, output voltage of $\mathrm{V}_{\mathrm{o}}=622$ $\mathrm{V}$ and $439 \mathrm{~V}$ can be obtained for a firing angle of $30^{\circ}$ and

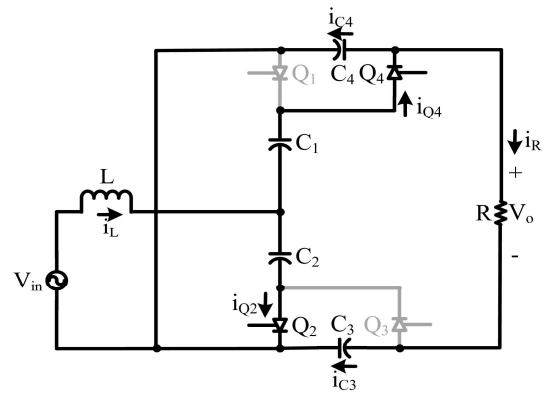

(b) phase 2

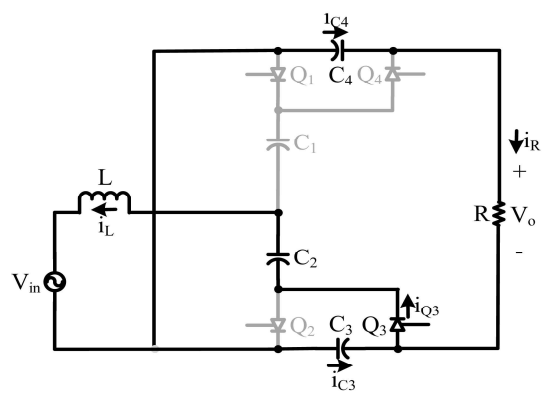

(d) phase 4

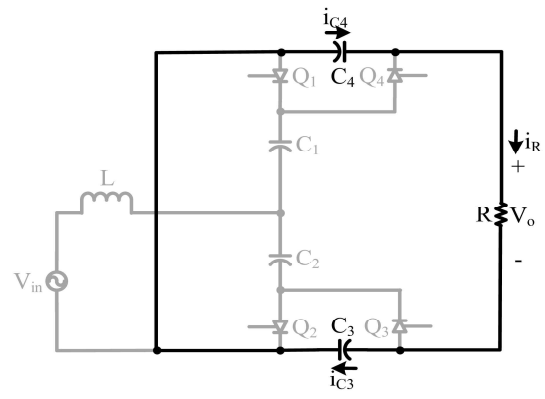

(f) phase 6

Fig. 4. Circuit operation principle in each period 
$135^{\circ}$, respectively.

The output voltage of the proposed circuit never reaches $4 \mathrm{~V}_{\mathrm{m}}$ under load condition owing to the poor voltage regulation of the voltage doubler [13]. According to [13], $\mathrm{V}_{\mathrm{drop}}$ can be expressed as follows:

$$
V_{d r o p}=2 \times\left[I_{\text {load }} /(6 f C)\right] \times\left(4 n^{3}+3 n^{2}-n\right)
$$

where $\mathrm{I}_{\text {load }}$ is the load current; $\mathrm{C}$, the output capacitance; $\mathrm{f}$, the input $\mathrm{AC}$ frequency; and $\mathrm{n}$, the number of stages (for

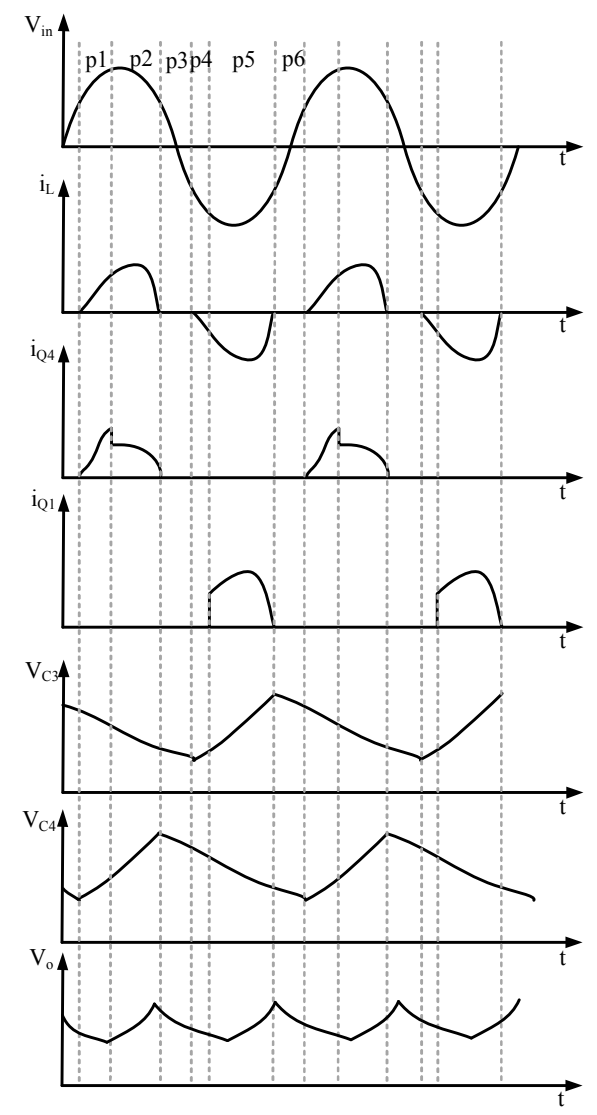

Fig. 5. Typical waveforms of the proposed circuit
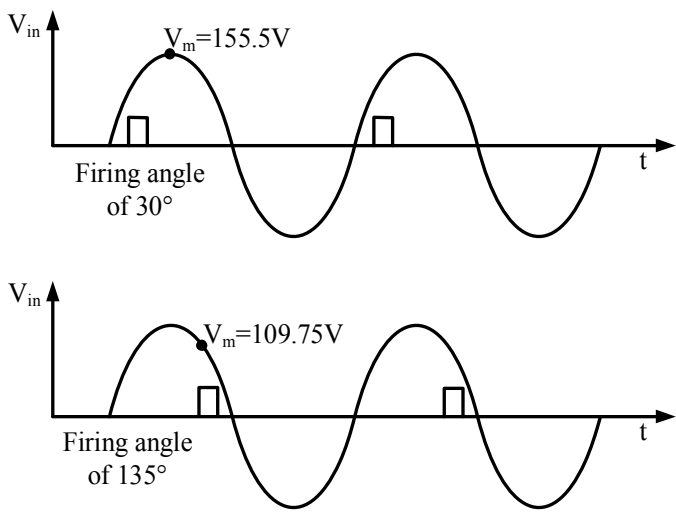

Fig. 6. $V_{m}$ under different firing angles

proposed circuit, $n=1)$. The output voltage under load condition is given as follows:

$$
V_{o}=4 \times V_{m}-V_{\text {drop }}
$$

\section{Design procedures}

The TCA785 phase control IC is used as the control chip for triggering the thyristor in the proposed circuit. Fig. 7 shows the full schematic of the driver circuit. Pin $\mathrm{V}_{\text {sync }}$ is the input for the synchronous voltage. Usually, this voltage is sensed from the input AC voltage. The switching signal of the thyristors is controlled by the chip to be synchronized with this AC voltage, which means that the firing angle should be constant. The supply voltage of TCA785 and two transistors is $10 \mathrm{~V}$ dc. These two transistors are operated as switches. The transistor and the connected isolation transformer are called a forwardconverter-type isolated driver because this driver is operated in a manner similar to a forward converter [14]. The design of the isolated transformer requires one to consider the voltage-second. This parameter also

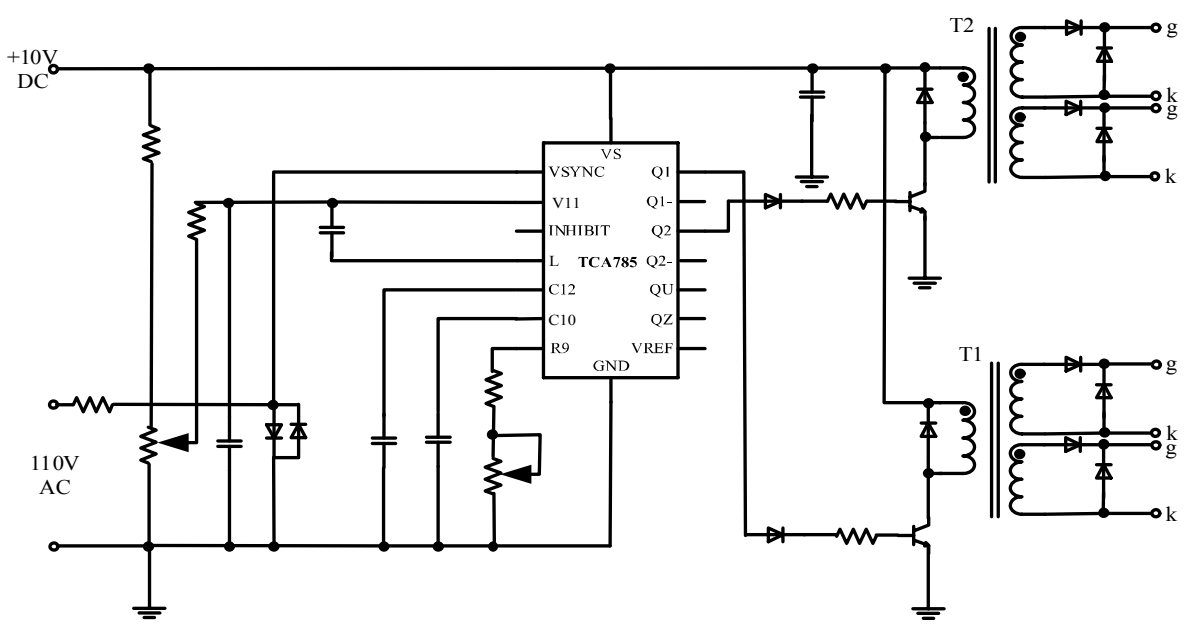

Fig. 7. Thyristor driver circuit for the proposed topology 


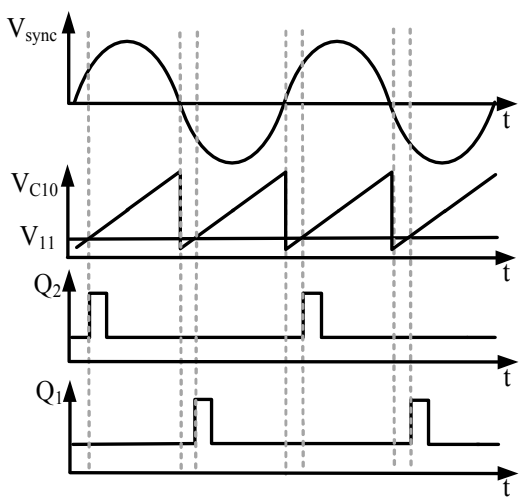

Fig. 8. Tuning principle of the firing angle

determines the core size of the transformer. For our circuit, a $30^{\circ}$ duration of the trigger signal is required, which means that the time is around $1.6 \mathrm{~ms}$. The thyristor has a minimum triggering voltage to turn on. With these two parameters, we can calculate the voltage-second to design the isolated transformer. TCA 785 has a function to change a thyristor's firing angle. The principle is shown in Fig. 8. $\mathrm{V}_{\text {sync }}$ is the synchronization voltage. $\mathrm{V}_{\mathrm{C} 10}$ is the ramp voltage. $\mathrm{Q}_{1}$ and $\mathrm{Q}_{2}$ are trigger signals. By tuning the variable resistor between $\mathrm{V}_{11}$ pin and ground in Fig. 7, the value of the control voltage $\mathrm{V}_{11}$ can be changed, and therefore, the firing angle can be changed.

\section{Simulation Verification}

PSIM is used to simulate our proposed circuit. Fig. 9 is the simulation result of the circuit under $110 \mathrm{~V}$ input voltage, $250 \Omega$ load and firing angle of $30^{\circ}$. It shows input voltage $V_{\text {in }}$, input current $I_{\text {in }}$, output voltage Vo and output capacitor voltage $\mathrm{V}_{\mathrm{c} 3}, \mathrm{~V}_{\mathrm{c} 4}$. From the figure we can find the output capacitor voltages are interleaved. Fig. 10 is the simulation result of the circuit under $110 \mathrm{~V}$ input voltage, no load and firing angle of $30^{\circ}$. After calculation, it can be

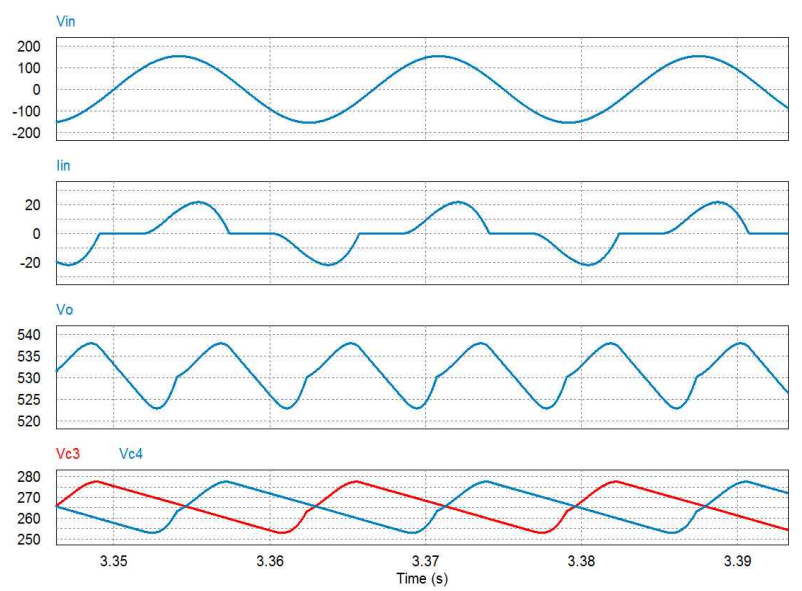

Fig. 9. Simulation results under $250 \Omega$ load and firing angle of $30^{\circ}$

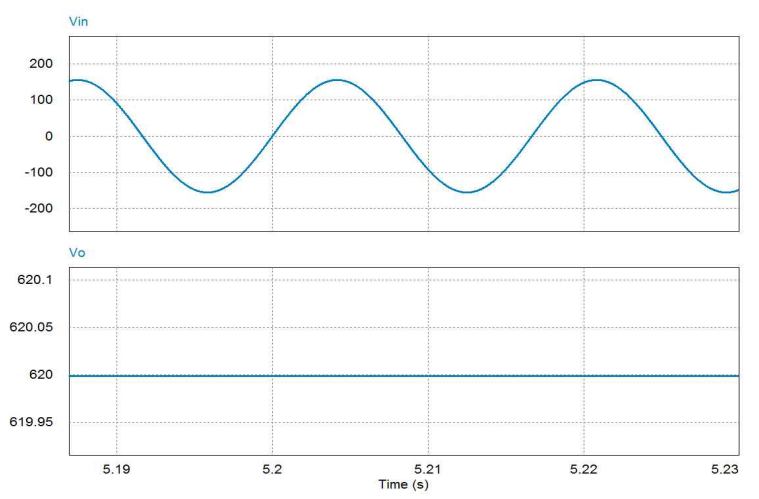

Fig.10. Simulation results under no load and firing angle of $30^{\circ}$

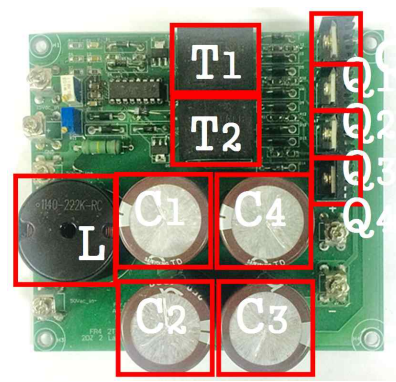

Fig. 11. Photograph of the proposed prototype circuit

found the simulation results matches theoretical analysis very well.

\section{Experimental Verification}

An experiment is conducted to verify the proposed circuit. A prototype, which has $110 \mathrm{~V}$ AC input voltage and $1000 \mathrm{~W}$ output power, is built for the experiment. Fig. 11 shows a photograph of the proposed prototype circuit. The circuit parameters are $\mathrm{C}_{1}=\mathrm{C}_{2}=\mathrm{C}_{3}=\mathrm{C}_{4}=1000 \mu \mathrm{F}$ and $\mathrm{L}=$ $2 \mathrm{mH}$. The experiment was carried out for firing angles of $30^{\circ}$ and $135^{\circ}$, respectively.

The experimental results with no load and with $250 \Omega$ load are shown in Figs. 12-15. The experiment result of the output voltage well coincides with our theoretical results as obtained in section 3. It can be seen that the output voltage can be regulated by changing the firing angle. Fig. 16 shows the interleaving of the output capacitor voltages. By this approach, the output voltage ripple of the circuit can be reduced sharply. The voltage ripple of one output capacitor is around $15 \%$, and it is reduced sharply to $6.6 \%$ by interleaving. The voltage stress over one output capacitor is also half of the output voltage, which reduces the output capacitor size. Fig. 17 shows the measured results of the efficiency and power factor of our circuit for $1000 \mathrm{~W}$ output power. The efficiency is more than $87 \%$, and the power factor is 0.8 . This power factor is relatively good for passive power factor correction [15-17]. 


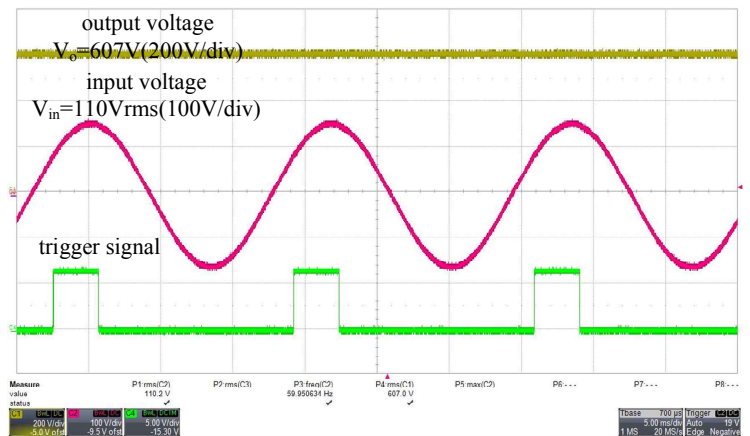

Fig. 12. Experimental results under no load condition and firing angle of $30^{\circ}$

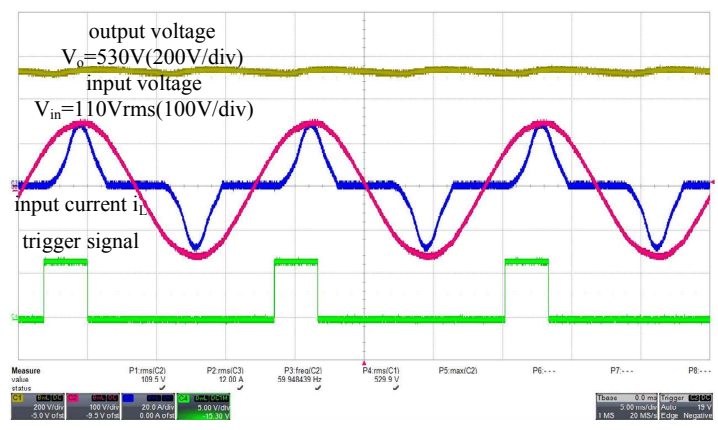

Fig. 13. Experimental results under $250 \Omega$ load and firing angle of $30^{\circ}$

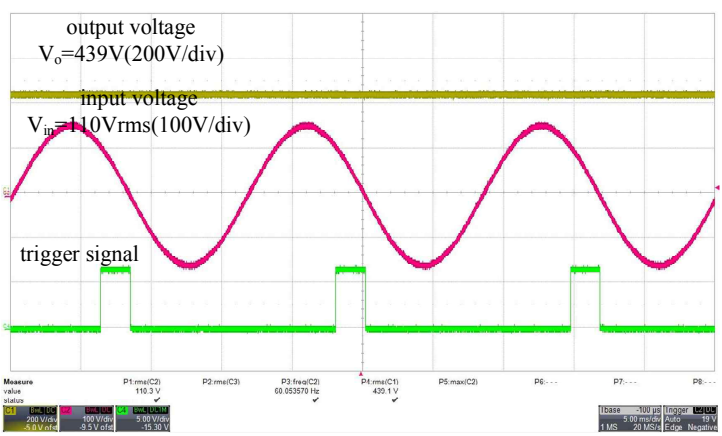

Fig. 14. Experimental results under no load condition and firing angle of $135^{\circ}$

\section{Conclusion}

In this paper, a single-stage bridgeless voltage rectifier based on a voltage doubler is proposed. This topology can achieve rectification, voltage step-up, and power factor correction functions in one stage. The circuit was analyzed theoretically, and its operational principle and experimental results were demonstrated. The experimental result agreed with the theoretical ones. However, the power factor is below 0.9 because of the use of passive power factor correction. This is a drawback that should be resolved in the future.

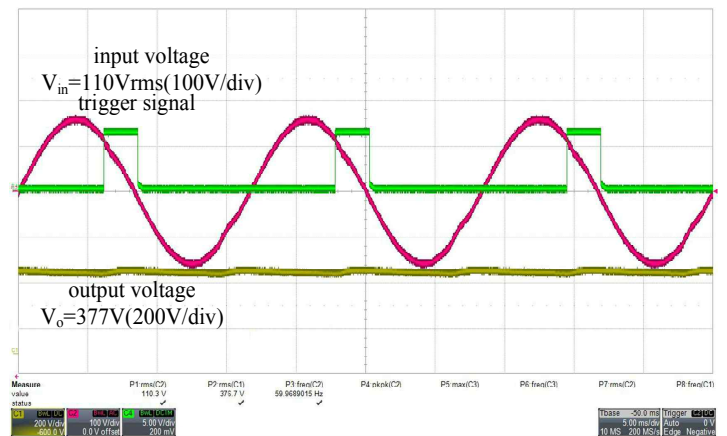

Fig. 15. Experimental results under $250 \Omega$ load and firing angle of $135^{\circ}$

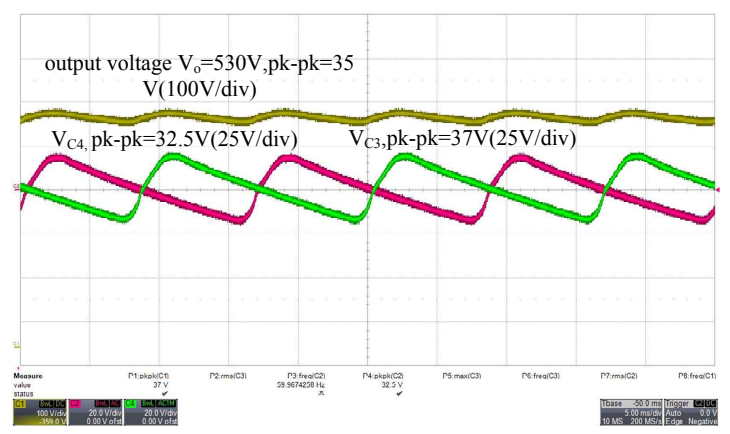

Fig. 16. Interleaving of two output capacitor voltages

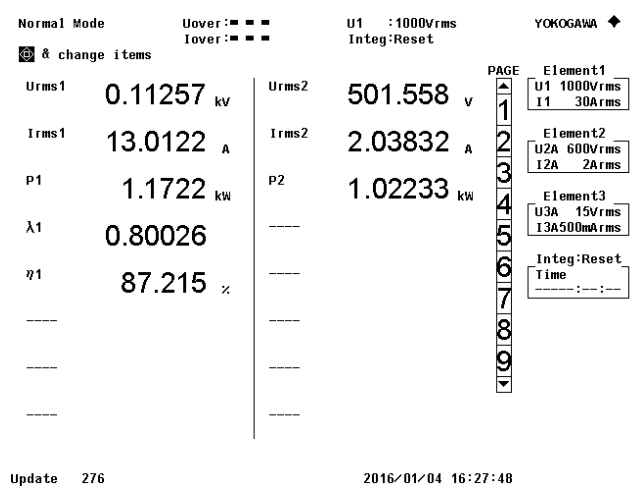

Fig. 17. Measured results of power efficiency and power factor under $250 \Omega$ load and $1000 \mathrm{~W}$ output power

\section{Acknowledgment}

This work was supported by the Human Resources Program in Energy Technology of the Korea Institute of Energy Technology Evaluation and Planning (KETEP), granted financial resource from the Ministry of Trade, Industry \& Energy, Republic of Korea. (20154030200730)

This work was supported by the Energy Efficiency \& Resources Department of the Korea Institute of Energy Technology Evaluation and Planning (KETEP) and was granted financial resources from the Ministry of Trade, Industry \& Energy, Republic of Korea (No. 20132010101950). 


\section{References}

[1] Bellar, M.D., Watanabe, E.H., Mesquita, A.C., "Analysis of the dynamic and steady-state performance of Cockcroft-Walton cascade rectifier", IEEE Trans. Power Electron., 1992, 7, (3), pp. 526-534

[2] Hwang, F., Shen, Y., Jayaram, S.H., "Low-ripple compact high-voltage dc power supply", IEEE Trans. Ind. Appl., 2006, 42, (5), pp. 1139-1145

[3] Iqbal, S., "A three-phase symmetrical multistage voltage multiplier", IEEE Power Electron. Lett., 2005, 3, (1), pp. 30-33

[4] Al-Kaabi, A. K., Fardoun, A. A., Ismail, E. H., "Bridgeless high voltage battery charger PFC rectifier", Renewable Energy, 2012, 10, 23

[5] Weiner, M.M., "Analysis of Cockcroft-Walton voltage multipliers with an arbitrary number of stages", Rev. Sci. Instrum., 1969, 40, (2), pp. 330-333

[6] Chung, H.J., "A CW $\mathrm{CO}_{2}$ laser using a high-voltage dc-dc converter with resonant inverter and CockroftWalton multiplier", Opt. Laser Technol., 2006, 38, (8), pp. 577-584

[7] Young, C.M., Chen, M.H., "A novel single-phase ac to high voltage dc converter based on CockcroftWalton cascade rectifier", Proc. Int. Conf. on IEEE Power Electronics and Drive Systems, Taipei, Taiwan, November 2009, pp. 822-826

[8] Siemens, "Phase Control IC", http://www.farnell.com/datasheets/1836360.pdf

[9] Young, C.-M., Chen, M.-H., Ko, C.-C., "High power factor transformerless single-stage single-phase ac to high-voltage dc converter with voltage multiplier", in Power Electronics, IET, Feb. 2012, 5, (2), pp.149157

[10] Sun, J., Ding, X., Nakaoka, M., Takano, H., “Series resonant ZCS-PFM DC-DC converter with multistage rectified voltage multiplier and dual-mode PFM control scheme for medical-use high-voltage X-ray power generator", IEE Proceedings on Electric Power Applications, Nov 2000, 147, (6), pp.527-534

[11] Malesani, L., Piovan, R., "Theoretical performance of the capacitor-diode voltage multiplier fed by a current source", IEEE Transactions on Power Electronics, Apr 1993, 8, (2), pp.147-155

[12] Surhone, L.M., Timpledon, M.T., Marseken, S.F., "Voltage Multiplier", VDM Publishing, Jul 14, 2010

[13] Blaze Labs Research, "Experiment 15-Cockcroft Walton voltage multiplier", http://blazelabs.com/ e-exp15.asp

[14] Trzynadlowski, A. M., "Introduction to Modern Power Electronics", John Wiley \& Sons, Oct 19, 2015

[15] Redl, R., “An economical single-phase passive power-factor-corrected rectifier: topology, operation, extensions, and design for compliance", Proceedings of the Thirteenth Annual IEEE Applied Power Elec- tronics Conference and Exposition 1998 (APEC'98), Vol. 1, 1998

[16] Detjen, D., "A new hybrid filter to dampen resonances and compensate harmonic currents in industrial power systems with power factor correction equipment", IEEE Transactions on Power Electronics 2001, 16, (6), pp. 821-827

[17] Garcia, O., "Single phase power factor correction: a survey", IEEE Transactions on Power Electronics, 2003, 18, (3), pp. 749-755

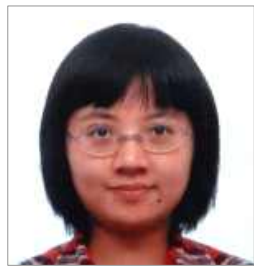

Yi Li received the B.S degree in control engineering from Harbin Institute of Technology, China, in 2010, and the M.S. degree in electrical engineering from the Ohio State University, United States in 2012. She is currently working toward the Ph.D. degree in electrical engineering with Hanyang University, Ansan, Korea. Her research interests are modeling for power converters and power factor correction.

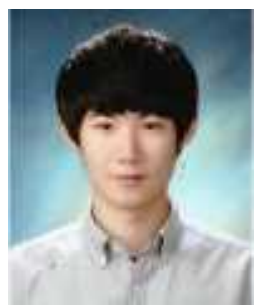

Joon-Hyeok Jeon received the B.S. degree in electronic and communication technology from the Mokpo National Maritime University, Mokpo, Korea, in 2014, and $\mathrm{He}$ is currently pursuing the Integrated Master and Ph.D. degree in electrical engineering with Hanyang University, Ansan, Korea His current research interests include $\mathrm{AC} / \mathrm{DC}$ converters for LED and DC/DC converter with GaN Transistors.

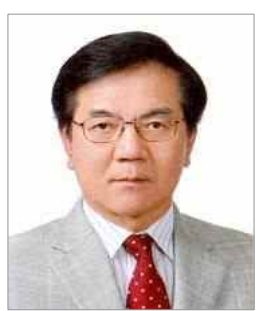

Hee-Jun Kim received the B.S and M.S. degree in electronics engineering from Hanyang University, Seoul, Korea, in 1976 and 1978, respectively, and the Ph.D. degree from Kyushu University, Fukuoka, Japan, in 1986, all in electronics engineering. Since 1987, he has been a Professor with Hanyang University, Ansan, Korea. His current research interests include switching power converters, soft-switching techniques, and analog signal processing. Prof. Kim is the President of the Korean Institute of Electrical Engineers in 2015 and a senior member of IEEE. 